\title{
Analysis of the heat sources detected by MODIS and VIIRS satellites in central western Amazonia
}

\author{
Vanusa de Souza Pacheco Hoki ${ }^{1,2}$ *, Luciana Sanches ${ }^{1}$, Pricila Juliana de Souza ${ }^{2}$, \\ Ana Carolina Freitas da Silva Taques ${ }^{2}$, Jonathan Willian Zangeski Novais ${ }^{2}$
}

\author{
${ }^{1}$ Universidade Federal de Mato Grosso (UFMT), Cuiabá, Mato Grosso, Brazil \\ ${ }^{2}$ Universidade de Cuiabá (UNIC), Cuiabá, Mato Grosso, Brazil \\ *e-mail: vanusahoki@gmail.com; 1sanches@ @otmail.com; souza.pricila123@gmail.com; \\ actaques@gmail.com; jonathanzangeski@gmail.com
}

\begin{abstract}
Forest fires are characterized as environmental disasters and depending on its gravity they destroy the entire forests causing ecosystem losses. The quality of the detection of heat sources in the satellite is relevant to verify the sources of fires and to assess the area to be reached, especially in areas of hard to reach such as those in the Brazilian Amazonia. This study was carried out in the municipality of Nova Ubiratã, Mato Grosso state and we aim to analyze the heat spots detected by two satellites between the months of may and october (dry season) from 2015 to 2018. The identification and quantification of the active heat sources were analyzed from the Database of the Instituto Nacional de Pesquisas Espaciais (INPE), detected by the AQUA satellites "Satellite Reference" Moderate Resolution Imaging Spectroradiometer (MODIS) with resolution of $1 \mathrm{~km}$ and Suomi-NPP (S-NPP) and Visible Infrared Imager Radiometer Suite (VIIRS) sensor with resolution of $375 \mathrm{~m}$ Outbreak data were analyzed. Our results indicated that the number of heat sources detected by the S-NPP overestimated the AQUA in $13.83 \%$, while the VIIRS detected 8.410 outbreaks, the MODIS sensor recorded 1.057 outbreaks. In addition to the fact that the S-NPP is a third generation satellite, the difference is due to the higher spatial resolution of $375 \mathrm{~m}$ of VIIRS with conditions to detect hot spots, while the spatial resolution of MODIS is $1 \mathrm{~km}$. We think that the interpretation of the data monitored by different satellites and sensors is fundamental for the effective decisionmaking of the fire analyst for fire management by forest fire prevention and control institutions.
\end{abstract}

Keywords: AQUA, satellite monitoring, Nova Ubiratã, reference satellite, S-NPP 